\title{
Christoph Rosenmüller y Stephan Ruderer (Editores). "Dádivas, do- nes y dineros."Aportes a una nueva historia de la corrupción en América Latina desde el imperio español a la modernidad. Madrid- Frankfurt am Main: Iberoamericana-Vervuert, 2016, 249 páginas.
}

\author{
Ignacio Zubizarreta ${ }^{1}$
}

$\mathrm{E}^{\mathrm{s}}$ studiar la historia de la corrupción es una misión tan interesante como arriesgada y difícil. Por un lado, la mayoría de las acciones ilícitas no suelen dejar rastros (al menos de las que los actores de la época interpretaban por tales buscando desaparecer las pruebas incriminatorias). Por otro, en muchos aspectos, parece un campo de estudios inédito y quienes en él se introduzcan deberán abrir nuevos horizontes no exentos de incertidumbres. También es difícil porque así lo es el poder establecer retrospectivamente el trazado de la línea que separa lo lícito de lo ilícito, lo moral de lo inmoral y lo disruptivo de lo cotidiano en sociedades que por lo distantes en el tiempo, mal podemos interpretarlas juzgando el comportamiento de sus agentes sin una previa y fina comprensión del contexto que le otorga sentido a sus acciones. Y finalmente, así como muchas veces son las problemáticas sociales actuales las que nos inducen a historiar su desarrollo a través de los siglos, la corrupción no es una más entre otras, pues conlleva una carga peyorativa en una ciudadanía latinoamericana continuamente sensible y hastiada por los escandalosos y recurrentes comportamientos que la prensa divulga sobre sus cuestionadas clases dirigentes. De este modo, colaborar a conformar y fortalecer una imagen de un pasado circular, desesperanzador, siempre corrupto y que no muta con el paso de los años, implica un ejercicio que seguramente quienes se propongan indagar sobre la historia de la corrupción latinoamericana querrán evitar a todo trance. Entre estos últimos, se encuentran Chistoph Rosenmüller y Stephan Ruderer, editores de una obra que se enmarca en lo que ellos mismos definen como una "nueva historia de la corrupción". El principal objetivo de su trabajo -y como las páginas de la introducción lo atestiguan-, radica en brindar una comprensión del fenómeno de la corrupción inserta en una postura anti-esencialista que, en vez de ofrecer una clara divisoria entre prácticas lícitas e ilícitas (con

1 Instituto de Estudios Socio-Históricos-Facultad de Ciencias Humanas-Universidad Nacional de La Pampa/Consejo

Nacional de Investigaciones Científicas y Técnicas. Argentina. Correo electrónico: ignzubizarreta@gmail.com 
su consecuente descripción y análisis del fenómeno), dilucida en qué medida la percepción social de la corrupción en una sociedad dada nos puede servir para entender mejor sus ideales políticos imaginados. Y con esa tarea como propósito, el nivel de complejidad se ve incrementado: no se trata ahora de constatar cuáles fondos públicos fueron desviados por quiénes y en qué montos, sino más bien buscar una comprensión cabal y abarcadora sobre la utilidad política que podía albergar una denuncia por corrupción, generalmente endilgada al oficialismo desde la oposición. De este modo, las acusaciones (basadas en hechos reales o ficticios, magnificados o minusvalorados) pueden reflejar, entre otros tantos, dos aspectos importantes: los límites de la tolerancia social hacia determinados comportamientos de sus elites; también, la capacidad de los actores políticos que no gobiernan para innovar en su capacidad discursiva creando características negativas en la imagen pública de sus circunstanciales antagonistas en el poder. En el análisis que ofrece "Dádivas, dones y dineros", el alcance temporal se extiende desde el antiguo régimen hasta mediados del siglo XX. El proceso de emancipación de España actúa como un verdadero parteaguas entre los extremos del largo lapso que ocupa la obra. Durante el período colonial, la diferencia entre espacio público y privado era sumamente más complejo que en su consecutivo; lo mismo cabe al concepto de opinión pública. A partir de la creación de las nuevas naciones latinoamericanas, los conceptos de soberanía popular y el nuevo rol de lo público irán transformando profundamente las percepciones sobre corrupción, acercándose así a una definición semejante a la vigente.

A pesar de que 249 páginas no componen un libro voluminoso, éste se encuentra fragmentado en numerosos y breves capítulos que visitaremos en el mismo orden en que se despliegan en la obra. En el primer capítulo, Prácticas corruptas o relaciones de patronazgo, Miguel Costa rescata un muy interesante conflicto entre el orden patrimonial individual de los funcionarios del virreinato del Perú y los intereses de la Monarquía a fines del siglo XVI. En cambio, en el segundo apartado, De lo innato a lo performativo: dos conceptos rivales de la corrupción, siglos XVII y XVIII, Christoph Rosenmüller analiza el nuevo ideal burgués de utilidad que se establece con el arribo de la dinastía borbona. Abriendo camino a un Estado eficientista y meritrocrático, éste se muestra de súbito contrario a las prácticas que desde ese momento pasarían a ser tildadas de corruptas por beneficiar a particulares y evitar enriquecer el erario de la Corona.

En Un interinato contra las prácticas corruptas en Acapulco..., Guadalupe Pinzón Ríos explica el breve lapso en el que la introducción de mercaderías desde Filipinas a Nueva España fue estrictamente controlada y penalizados los 
infractores en dicho tráfico. No obstante, estas políticas anti-corruptas de la Corona semejan esporádicas y jamás se sostienen en el largo plazo, lo que invita a preguntarse el por qué y, lamentablemente, eso no se responde en el capítulo en cuestión.

En un escrito excesivamente autorreferencial titulado Un epílogo: "соrrupción" en el virreinato novohipano, Horst Pietschmann brinda una confusa síntesis sobre sus investigaciones relativas al fenómeno general de la corrupción. No resulta claro si el foco de su interés se centra en el México colonial o en el actual, si se trata de un compendio o más bien una reflexión sobre sus propios trabajos; evidentemente, no representa un aporte sustancial a la obra.

En el capítulo La defensa libre, el monopolio de los abogados y la corrupción en el Perú, Pablo Whipple presenta un debate de mediados del siglo XIX sobre la conveniencia de permitir la libertad de defensa amparada en la escasez de letrados en las localidades de provincia, contrarrestadas por el lobby de un colegiado molesto ante la posibilidad de perder su exclusividad. No parece ser la corrupción un tema sino colateral, en el sentido que entre dos posturas políticas/corporativas o de grupos de interés, ambas endilgaban el rótulo de corrupta a la otra; más allá de constatar ese hecho, el trabajo habla poco de las prácticas ilícitas como de la percepción de las mismas, y la conclusión, paradójicamente, es un compendio de las propias falencias y de los aspectos que faltan desarrollar, reflejando lo incipiente de la investigación en cuestión.

Resulta muy interesante el análisis que realiza Stephan Ruderer en Corrupción y violencia en Argentina y Uruguay en el siglo XIX. En él destaca cómo los conceptos de "corrupción" y "violencia" eran vertidos en verdaderos combates discursivos, ora por el elenco gobernante para deslegitimar a sus opositores de violentos y anarquistas, ora por sus antagonistas para justificar movimientos insurreccionales que pudiesen poner término a gestiones supuestamente corrompidas. Este estudio parangona los casos de dos países que tienen una raigambre política común; no obstante, destaca el proceso en el que en Uruguay se comenzó a interpretar por "corrupto" un gobierno que malversaba fondos públicos, mientras que en Argentina ese mismo concepto condensaba más puntualmente el fraude electoral. Era el acceso al poder lo que se cuestionaba en este último país, mientras que en Uruguay lo eran las prácticas del gobierno en ejercicio, pasando a segundo orden el modo en que sus funcionarios alcanzaban dicho poder. En el capítulo El triunfo moral del Pueblo..., de María Inés Rojkind, la autora examina con solvencia las particularidades de la renuncia del poder del presidente argentino Miguel Juárez Celman (1890) y la movilización social que potenció las causas de su dimisión y las que se llevaron a cabo para celebrar ese hecho de enorme trascendencia política. 
La corrupción en los gobiernos locales del México porfiriano..., de Andrés Reyes Rodríguez, aborda una temática cuyo título no refleja el verdadero contenido del escrito, más bien, brinda un análisis sobre el rol electoral que cumplió la imagen pública de honradez en el caso puntual del gobernador de Aguascalientes Rafael Arellano a fines del siglo XIX. Las conclusiones que presenta son poco convincentes y el propio autor remarca todo lo que le quedó en el tintero en materia investigativa para pulir su propuesta.

El apartado Poder político y corrupción en la Revolución mexicana..., de Jürgen Buchenau, responde a una historiografía que tildó de corrupta a la elite revolucionaria con Álvaro Obregón a la cabeza, en donde se demuestra que ese enriquecimiento distó mucho de ser tan abultado y probablemente eso se debió a la incapacidad del mismo Obregón por mantener su influjo cuando se encontró por fuera de la cúspide del poder. José Alberto Olivar, en la última sección de la obra, denominada El Jurado de Responsabilidad Civil y Administrativa 1946: Ramón Cárdenas, busca demostrar el desprestigio que le generó al ex ministro venezolano Ramón Cárdenas el figurar en un listado de supuestos corruptos elaborado por el régimen político que le sucedió. Su autor no logra resaltar el motivo por el cuál la problemática de la investigación tiene relevancia.

En conclusión, la obra conlleva un acierto remarcable: el tema de investigación y la propuesta original de los compiladores configuran un desafío historiográfico mayúsculo. Los estudios sobre la historia de la corrupción responden y fomentan la comprensión de un fenómeno harto complejo donde las sociedades latinoamericanas buscan respuestas y donde, paralelamente, existe un vacío de literatura actual sobre la temática. Asimismo, quisiera destacar dos críticas al conjunto del trabajo. Por un lado, casi la mitad de sus capítulos están abocados a Nueva España o México, reflejando una menor representatividad sobre otras regiones latinoamericanas. Y por último, como sucede en la mayoría de las obras de compilación (y que esto ocurra con tanta frecuencia no exime la crítica), encontramos una enorme disparidad en la calidad de los diversos capítulos: desde estudios demasiado preliminares o inconsistentes hasta trabajos magistrales de síntesis. A pesar de lo dicho, este libro es más que bienvenido y representará una lectura obligada para quienes quisieran comprender mejor las causas de un fenómeno tan constante y con tanta repercusión social como la corrupción de las elites gobernantes latinoamericanas. 